\title{
Spatial Heterogeneity in Sensitivity of Evapotranspiration to Climate Change
}

\author{
Henian Wang1, ${ }^{1,2}$ Manyin Zhang ${ }^{1,2 *}$, Lijuan Cui ${ }^{1,2}$, Xinxiao $\mathrm{Yu}^{3}$ \\ ${ }^{1}$ Institute of Wetland Research, Chinese Academy of Forestry, Beijing, 100091, China \\ ${ }^{2}$ Beijing Key Laboratory of Wetland Services and Restoration, Beijing, 100091, China \\ ${ }^{3}$ Beijing Forestry University, Beijing, 100083, China
}

Received: 17 March 2017

Accepted: 10 April 2017

\begin{abstract}
Long-term water-energy balance is a major concern in hydrology and water resource management. Evapotranspiration is a key factor for achieving water-energy balance. In this study, we used a simple water and energy balance equation to compare the effects of precipitation and potential evapotranspiration on actual evapotranspiration - mathematically and theoretically. The results showed that, in Baiyangdian catchment, a $1 \mathrm{~mm}$ or $10 \%$ increase in precipitation would lead to a $0.51 \mathrm{~mm}$ or $6.6 \%$ in actual evapotranspiration, and a $1 \mathrm{~mm}$ or $10 \%$ increase in potential evapotranspiration would lead to a $0.14 \mathrm{~mm}$ or $3.4 \%$ in actual evapotranspiration. The regional differences in the 10 regions of China showed that the effects of climate on actual evapotranspiration were significantly influenced by the aridity index. The changes of potential evapotranspiration will lead to more changes in actual evapotranspiration in humid regions, and the changes of precipitation will lead to more changes in actual evapotranspiration in arid regions.
\end{abstract}

Keywords: sensitivity, evapotranspiration, precipitation, potential evapotranspiration

\section{Introduction}

A long-term estimation of water balance is very important to: 1) understand the hydrological cycles over large temporal scales, 2) describe the dynamics of hydrological systems, and 3) predict the rapidly changing trends of hydro-climatic variables [1]. Water balance is a most basic and important concept for catchment hydrology. Moreover, it is a common concept for studying hydrological behaviors [2-5]. One of the core questions for estimating long-term water balance is the partition of mean annual precipitation into mean annual evapotranspiration and mean annual streamflow [6]. Until

*e-mail: submission2013@126.com now, none of the methods has been developed for directly measuring evapotranspiration on a large spatial scale [2].

In recent times, climate change and human activities have led to a large change in hydrological processes and water availability in many regions of the world [710]. The link between climate change and hydrological response is one of the main questions to be researched in the past and even today in hydrology. Many attempts have been made to formulate the mean annual water-energy balance [11-14]. Budyko (1974) assumed that the actual evapotranspiration is a function of the aridity index and precipitation, and it can be expressed as $E / P=f\left(E_{0} / P\right)$ [15].

The energy-based theoretical equations, which describe the climate and the water balance, have been developed and applied in a "top-down" fashion [16-18]. The developments of Budyko (1974) and Fu' (1981) [19] 


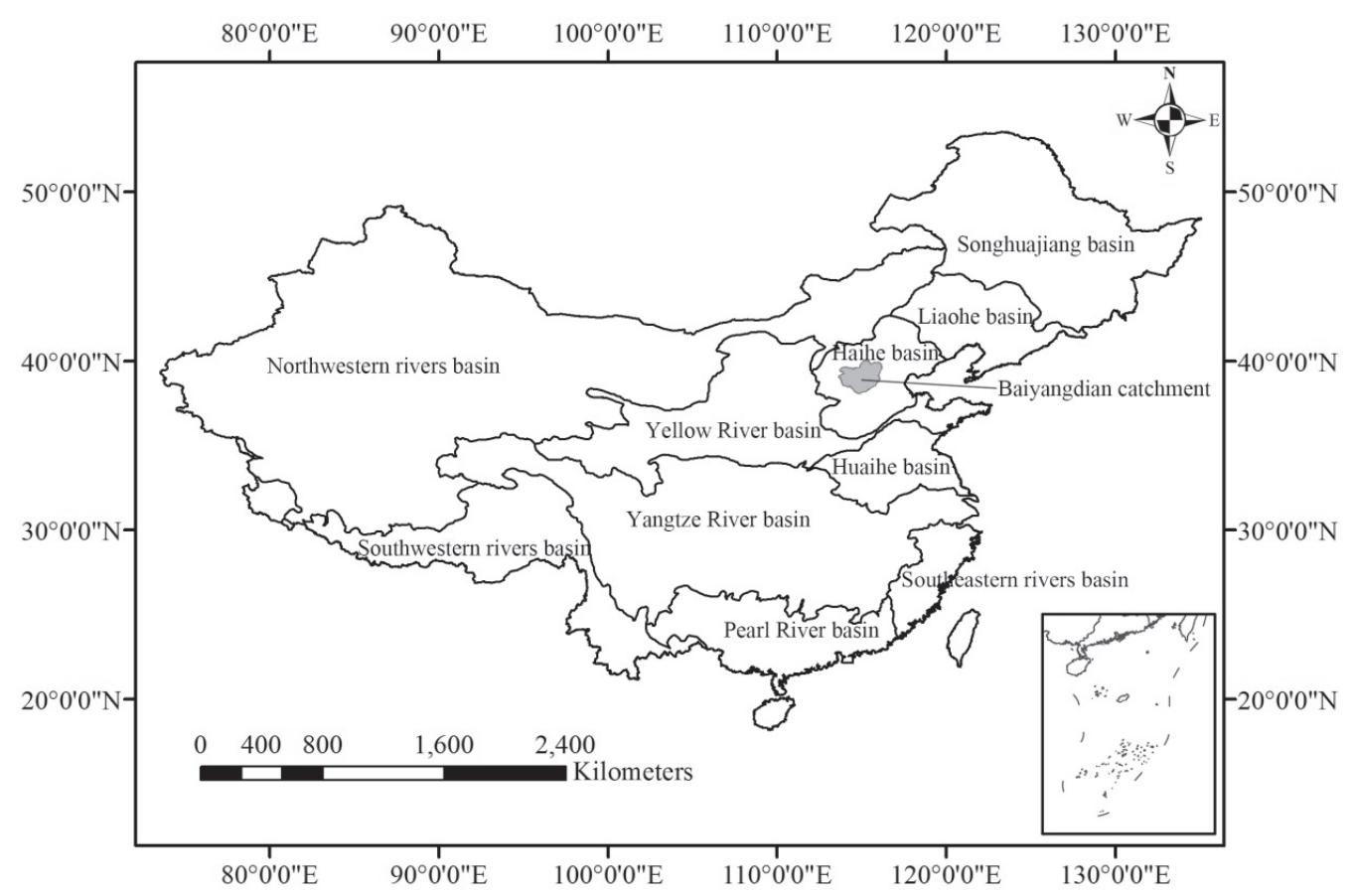

Fig. 1. Locations of the 10 regions and Baiyangdian catchment.

have received wide publication, and, therefore, both of them have added a new catchment-specific parameter. Renner et al. (2012) developed a similar equation [14], which is very simple for the purposes of estimation. The aforesaid equation can be used to predict the effects of climate change on streamflow.

In this article, a theoretical pattern of the dependence for the aridity index $\left(\phi=E_{\delta} / P\right)$ and the catchment characteristics on the basis of Renner's equation are analyzed. The aim of the research is to discuss the effects of climate on evapotranspiration by evaluating Renner's water-energy balance framework, and to show the variances of different regions and of different climatic conditions.

\section{Materials and Methods}

\section{Study Area}

According to the water resources first-level division, China could be divided into 10 basin regions: Songhuajiang, Liaohe, Haihe, Yellow River, Huaihe, Yangtze River, southeastern rivers, Pearl River, southwestern rivers, and northwestern rivers. The location and scale of each basin is shown in Fig. 1, and some information about them is shown in Table 1.

The Baiyangdian catchment is located in the middle of the Haihe basin, bounded by $37^{\circ} 48^{\prime}-40^{\circ} 24^{\prime} \mathrm{N}$ and $113^{\circ} 18^{\prime}$ $116^{\circ} 36^{\prime} \mathrm{E}$ (Fig. 1). It covers an area of $31,200 \mathrm{~km}^{2}$, and

Table 1 . Some information of the 10 regions.

\begin{tabular}{|c|c|c|c|c|c|c|c|}
\hline ID & Regions & Area $\left(\mathrm{km}^{2}\right)$ & $\begin{array}{c}\mathrm{P} \\
(\mathrm{mm})\end{array}$ & $\begin{array}{c}\mathrm{Q} \\
(\mathrm{mm})\end{array}$ & $\begin{array}{c}\mathrm{E} \\
(\mathrm{mm})\end{array}$ & $\begin{array}{c}\mathrm{E}_{0} \\
(\mathrm{~mm})\end{array}$ & \begin{tabular}{c}
$\phi$ \\
\hline 1
\end{tabular} \\
\hline 2 & Songhuajiang basin & 93.5 & 461 & 134 & 327 & 730 & 1.58 \\
\hline 3 & Liaohe basin & 31.4 & 514 & 138 & 376 & 870 & 1.69 \\
\hline 4 & Haihe basin & 32 & 490 & 81 & 409 & 970 & 1.97 \\
\hline 5 & Yellow River basin & 79.5 & 443 & 79 & 364 & 950 & 2.14 \\
\hline 6 & Huaihe basin & 33 & 869 & 314 & 555 & 990 & 1.13 \\
\hline 7 & Yangtze River basin & 180 & 1,055 & 532 & 523 & 830 & 0.78 \\
\hline 8 & Southeastern rivers basin & 24.5 & 1,663 & 944 & 719 & 950 & 0.57 \\
\hline 9 & Pearl River basin & 57.8 & 1,536 & 811 & 725 & 1,000 & 0.65 \\
\hline 10 & Southwestern rivers basin & 84.4 & 1,071 & 667 & 404 & 1,050 & 0.98 \\
\hline
\end{tabular}


mountainous and plain areas account for about $60 \%$ and $40 \%$, respectively. The topography is characterized by low mountains in the west and plains in the east. This region has a warm-temperate monsoon climate, the mean annual temperatures are $7.4^{\circ} \mathrm{C}$ in the mountainous area and $12.7^{\circ} \mathrm{C}$ in the plain area, and mean annual precipitation is $563 \mathrm{~mm}$ (with about $80 \%$ distributed between July and September). Its mean annual pan evaporation is $1,500-2,000 \mathrm{~mm}$.

\section{Data}

The annual precipitation and streamflow data of the 10 basins were obtained from the "water resources bulletin" (1997-2015) of each basin, respectively. The aridity index data of China was derived from the National Science and Technology Infrastructure of China, the National Earth System Science Data Sharing Infrastructure (www.geodata.cn). The annual runoff data (1960-2010) of Baiyangdian catchment were obtained from the Hydrological Yearbook of the People's Republic of China. And the annual precipitation and potential evapotranspiration data (1960-2010) of the catchment were obtained from the national weather station of Baoding via the China Meteorological Data Sharing Service System (cma.gov.cn).

\section{Methods}

\section{Water-Energy Balance with CCUW Hypothesis}

Tomer and Schilling (2009) employed the two nondimensional variables, i.e., relative excess water $(W)$ and relative excess energy $(U)$ [20], to establish a framework to reflect the hydro-climatic state of a given catchment. These two variables were mathematically derived and are shown as follows:

$$
W=1-\frac{E}{P}, U=1-\frac{E}{E_{0}}
$$

...where $E_{0}$ is mean annual potential evapotranspiration and $W$ and $U$ denote the proportions of the available water and energy that are unused, i.e., in excess of the requirements.

Tomer and Schilling (2009) have introduced a conceptual model based on the hypothesis that the direction of a temporal change in a relationship between $U$ and $W$ can be used to distinguish the effects of a change in the patterns of land use and climate on a water budget in a given basin [20]. The conceptual model states that the changes in the climate and basin characteristics qualitatively lead to a different change in partitioning the water $(W)$ and the energy $(U)$ at the surface. A change in the climatic conditions of a long-term average, i.e., $P$ and $E_{0}$, would lead to the changes of the $U$ and the $W$ in an opposite direction. By taking this assumption, Renner and Bernhofer (2012) [14] have concluded that:

$$
\Delta U / \Delta W=-1
$$

The aforementioned hypothesis can be abbreviated as "CCUW."

On the basis of the definition of the $\mathrm{W}$ and the $\mathrm{U}$, their change in the two different periods can mathematically be expressed by virtue of equation (3), and it can be shown as follows:

$$
\Delta W=\frac{E_{1}}{P_{1}}-\frac{E_{2}}{P_{2}}, \Delta U=\frac{E_{1}}{E_{0,1}}-\frac{E_{2}}{E_{0,2}}
$$

....and, in accordance with equation (4), it may be changed as follows:

$$
\Delta U+\Delta W=0
$$

Thereafter, we can get:

$$
\frac{E_{1}}{P_{1}}+\frac{E_{1}}{E_{0,1}}=\frac{E_{2}}{P_{2}}+\frac{E_{2}}{E_{0,2}}
$$

n.e.:

$$
\frac{E}{P}+\frac{E}{E_{0}}=C_{E}=\text { const }
$$

It is important to note that the sum of $(E / P)$ and $\left(E / E_{0}\right)$ for a given basin is constant. And that constant is called catchment efficiency $\left(C_{E}\right)$.

Re-arranging equation (8), we get:

$$
\frac{E}{P}=C_{E} \cdot \frac{E_{0}}{P+E_{0}}
$$

Then Renner et al. (2012) [14] developed this new water-energy balance that could be used on long-term time and catchment scales, and could be used to predict the mean annual evapotranspiration of a catchment.

$$
\text { Sensitivity Coefficient of } E \text { to } P \text { and } E_{0}
$$

The sensitivity concept, as described by Schaake and Liu (1989) [22], shows that the relative changes in a streamflow are proportional to the inverse of the runoff ratio (i.e., $P / Q$ ). As has been shown in an analytical equation, Equation (9) can be differentiated with respect to $P$ or $E_{0}$. The partial derivatives describe the effect of a hydrological cycle as a result of rapidly changing $P$ and/or $E_{0}$, which can be written as follows: 


$$
\left\{\begin{array}{l}
\frac{\partial E}{\partial P}=C_{E} \cdot\left(\frac{E_{0}}{P+E_{0}}\right)^{2}=C_{E} \cdot\left(\frac{\frac{E_{0}}{P}}{1+\frac{E_{0}}{P}}\right)^{2} \\
\frac{\partial E}{\partial E_{0}}=C_{E} \cdot\left(\frac{P}{P+E_{0}}\right)^{2}=C_{E} \cdot\left(\frac{1}{1+\frac{E_{0}}{P}}\right)^{2}
\end{array}\right.
$$

...where $\partial E / \partial P$ represents the change in actual evapotranspiration $(E)$ divided by the change in precipitation $(P)$. Similarly, $\partial E / \partial E_{0}$ represents the change in the actual evapotranspiration $(E)$ divided by the change in potential evapotranspiration $\left(E_{0}\right)$.

And, we also used the elasticity coefficient $(\varepsilon)$ to represent a proportional change in the evapotranspiration $(E)$ divided by the proportional change in a climatic variable $(X)$, such as precipitation $(P)$ or potential evapotranspiration $\left(E_{0}\right)(16)$. It can be written as follows:

$$
\varepsilon=\frac{\partial E / E}{\partial X / X}=\frac{\partial E}{\partial X} \cdot \frac{X}{E}
$$

In accordance with equations (19) and (20), the elasticity coefficient of the evapotranspiration to the precipitation $\left(\varepsilon_{P}\right)$ and the potential evapotranspiration $\left(\varepsilon_{E_{0}}\right)$ can be obtained as follows:

$$
\left\{\begin{array}{l}
\varepsilon_{P}=\frac{\partial E}{\partial P} \cdot \frac{P}{E}=C_{E} \cdot\left(\frac{E_{0}}{P+E_{0}}\right)^{2} \cdot \frac{P}{C_{E} \cdot \frac{P \cdot E_{0}}{P+E_{0}}}=\frac{E_{0}}{P+E_{0}}=\frac{\phi}{1+\phi} \\
\varepsilon_{E_{0}}=\frac{\partial E}{\partial E_{0}} \cdot \frac{E_{0}}{E}=C_{E} \cdot\left(\frac{P}{P+E_{0}}\right)^{2} \cdot \frac{E_{0}}{C_{E} \cdot \frac{P \cdot E_{0}}{P+E_{0}}}=\frac{P}{P+E_{0}}=\frac{1}{1+\phi}
\end{array}\right.
$$

\section{State Space of the Water-Energy Balance Equation}

Fig. 4 shows the curves of the CCUW hypothesis for different values of $C_{E}$. These curves are strongly determined by virtue of a $C_{E}$, which are similar to determine the effect of different values for catchment parameter $w$ in a parameterized Fu's theoretical equation [14, 19, 23].

Under extreme wet conditions, the $E$ approaches the $\mathrm{E}_{0}$, and, thereafter, it would not increase with precipitation $(P)$, because of the condition that the $\mathrm{E}$ is limited by potential evapotranspiration $\left(E_{0}\right)$. Whereas under extreme dry conditions, E approaches precipitation $(P)$ and, thereafter, it would not increase with potential evapotranspiration $\left(E_{0}\right)$. As has been shown in Fig. 1, the two asymptotes join at point $\mathrm{A}$, at which $E, P$, and $E_{0}$ are equal; $\mathrm{OA}$ is the wet edge at which $E=E_{0}$, and $\mathrm{AB}$ is the dry edge at which $E=P$.

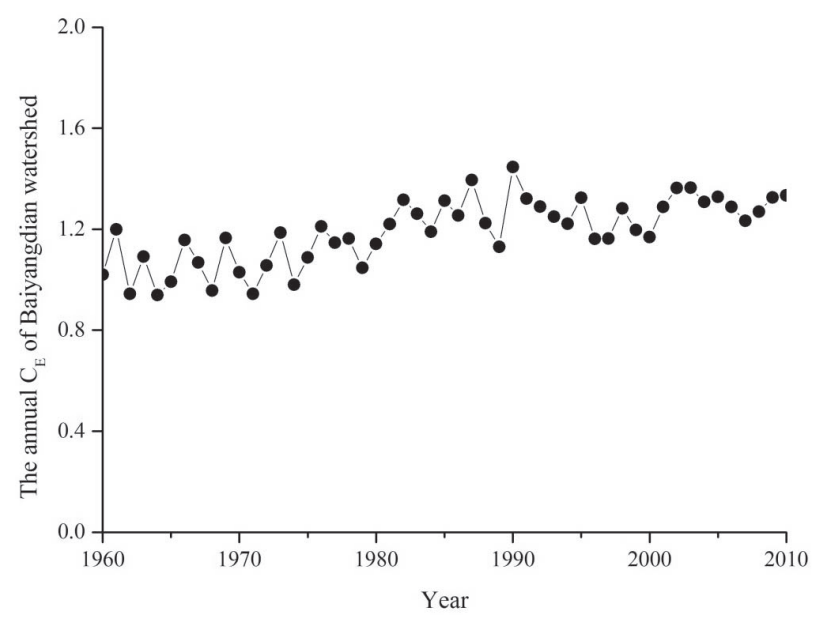

Fig. 2. Annual $C_{E}$ of Baiyangdian catchment from 1960 to 2010 .

In accordance with the Budyko space of $(E / P)$ and $\left(E_{0} / P\right)$, there is an energy limit (i.e., $\left.y=x\right)$ and a water limit (i.e., $y=1$ ), which are based on the fact that $E<P$ and $E<E_{0}$ [24-26]. In many conditions, as shown in Fig. 4 , the curves of the CCUW-based hypothesis overstepped the aforementioned two limiting boundary lines [27-28], which can mathematically be expressed as:

$$
\left\{\begin{array}{c}
\frac{E}{P}=C_{E} \cdot \frac{E_{0}}{P+E_{0}}<1 \\
\frac{E}{P}=C_{E} \cdot \frac{E_{0}}{P+E_{0}}<\frac{E_{0}}{P} \\
C_{E}=\frac{E}{P}+\frac{E}{E_{0}}<2
\end{array}\right.
$$

Then the limits of $C_{E}$ can be written as:

$$
\begin{cases}C_{E}<1+\frac{E_{0}}{P} & \left(\text { when } \quad \frac{E_{0}}{P} \leq 1\right) \\ C_{E}<1+\frac{P}{E_{0}} & \left(\text { when } \quad \frac{E_{0}}{P} \geq 1\right)\end{cases}
$$

\section{Results and Discussion}

\section{Application and Verification of CCUW Hypothesis in Baiyangdian Catchment}

Just a single parameter of the mean annual waterenergy balance equation represents the integrated effects of the catchment and of the vegetation characteristics, which have a significant effect on evapotranspiration. This parameter mainly includes the plant-available water, the average slope, land use, vegetation cover, etc. Renner et al. (2012) has called that parameter the $C_{E}$ (i.e., catchment efficiency) [14], which was calibrated using 


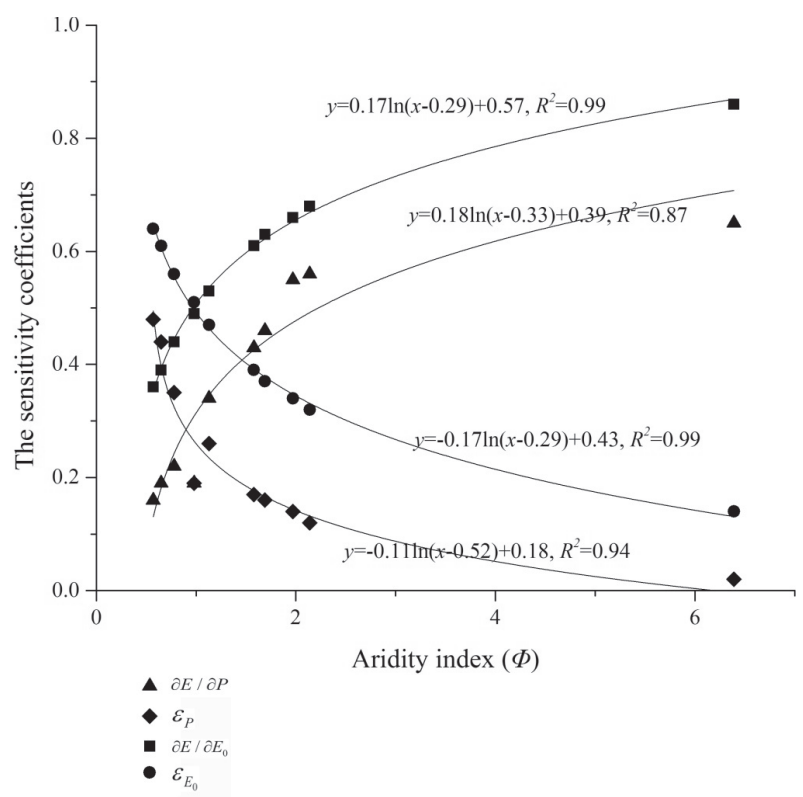

Fig. 3. Relationships between sensitivity coefficients and aridity index.

the data of annual precipitation, actual evapotranspiration, and potential evapotranspiration in the catchment. Fig. 2 showed the annual $C_{E}$ of Baiyangdian from 1960 to 2010, and suggested a mean value of 1.20. The Mann-Kendall change point test (not shown here) of the $C_{E}$ parameter indicates an abrupt change in 1980 at the 0.05 significance level. Analysis of the $C_{E}$ in 1960-80 and 1981-2010 suggests that, it both had obviously constant trends in these two periods, respectively, and this verified the theory of CCUW hypothesis and equation (6), so it could be applied in the following analysis.

Table 2. The sensitivity and elasticity coefficients of the 10 regions in China.

\begin{tabular}{|c|c|c|c|c|c|}
\hline Regions & $\phi$ & $\partial E / \partial P$ & $\partial E / \partial E_{0}$ & $\varepsilon_{E}$ & $\varepsilon_{E 0}$ \\
\hline $\begin{array}{c}\text { Songhuajiang } \\
\text { basin }\end{array}$ & 1.58 & 0.43 & 0.17 & 0.61 & 0.39 \\
\hline Liaohe basin & 1.69 & 0.46 & 0.16 & 0.63 & 0.37 \\
\hline Haihe basin & 1.97 & 0.55 & 0.14 & 0.66 & 0.34 \\
\hline $\begin{array}{c}\text { Yellow River } \\
\text { basin }\end{array}$ & 2.14 & 0.56 & 0.12 & 0.68 & 0.32 \\
\hline $\begin{array}{c}\text { Huaihe basin } \\
\text { Yangtze River } \\
\text { basin }\end{array}$ & 1.13 & 0.74 & 0.26 & 0.53 & 0.47 \\
\hline $\begin{array}{c}\text { Southeastern } \\
\text { rivers basin }\end{array}$ & 0.57 & 0.16 & 0.48 & 0.36 & 0.64 \\
\hline $\begin{array}{c}\text { Pearl River } \\
\text { basin }\end{array}$ & 0.65 & 0.19 & 0.44 & 0.39 & 0.61 \\
\hline $\begin{array}{c}\text { Southwestern } \\
\text { rivers basin }\end{array}$ & 0.98 & 0.19 & 0.19 & 0.49 & 0.51 \\
\hline $\begin{array}{c}\text { Northwestern } \\
\text { rivers basin }\end{array}$ & 6.39 & 0.65 & 0.02 & 0.86 & 0.14 \\
\hline
\end{tabular}

Table 3. The correlation analysis between the sensitivity coefficients and $\phi$.

\begin{tabular}{|c|c|c|c|c|}
\hline & $\partial E / \partial P$ & $\partial E / \partial E_{0}$ & $\varepsilon_{E}$ & $\varepsilon_{E_{0}}$ \\
\hline $\begin{array}{c}\text { Pearson } \\
\text { correlation }\end{array}$ & $0.776^{* *}$ & $-0.729^{* *}$ & $0.875^{* *}$ & $-0.875^{* *}$ \\
\hline Significance & 0.000 & 0.000 & 0.000 & 0.000 \\
\hline
\end{tabular}

${ }^{* *}$ Correlation is significant at the 0.01 level

$C_{E}$ was named "catchment efficiency," and its change reflects the change of catchment characteristics. The Mann-Kendall test result of $C_{E}$ showed an abrupt change in 1980, and that means the characteristics of Baiyangdian catchment had some changes that year. A comparison of these two periods showed that the $C_{E}$ in 1981-2010 (the mean value was 1.08 ) was slightly bigger than in 1960-80 (the mean value was 1.27). In 1980, China's Three-North Shelterbelt Program came into operation, and the forest coverage improved greatly in the study area. The increase of forest area made actual evapotranspiration have an increase, and this might be the reason for the increase of $C_{E^{*}}$

\section{The Sensitivity Analysis of $E$ to $P$ and $E_{0}$ and its Regional Differences}

\section{The Sensitivity of $E$ to $P$ and $E_{0}$}

The sensitivity and elasticity coefficients of actual evapotranspiration to precipitation and potential evapotranspiration were determined by equations (8) and (10). The values of $\partial E / \partial P$ and $\partial E / \partial E_{0}$ of Baiyangdian catchment were 0.51 and 0.14 , respectively, and indicated that a $1 \mathrm{~mm}$ increase in $P$ would result in $0.51 \mathrm{~mm}$ in actual evapotranspiration, while a $1 \mathrm{~mm}$ increase in $E_{0}$ would result in $0.14 \mathrm{~mm}$ in actual evapotranspiration. And the values of $\varepsilon_{P}$ and $\varepsilon_{E_{0}}$ of Baiyangdian catchment were 0.66 and 0.34 , respectively, and indicated that a $10 \%$ increase in $P$ would result in $6.6 \%$ in actual evapotranspiration,

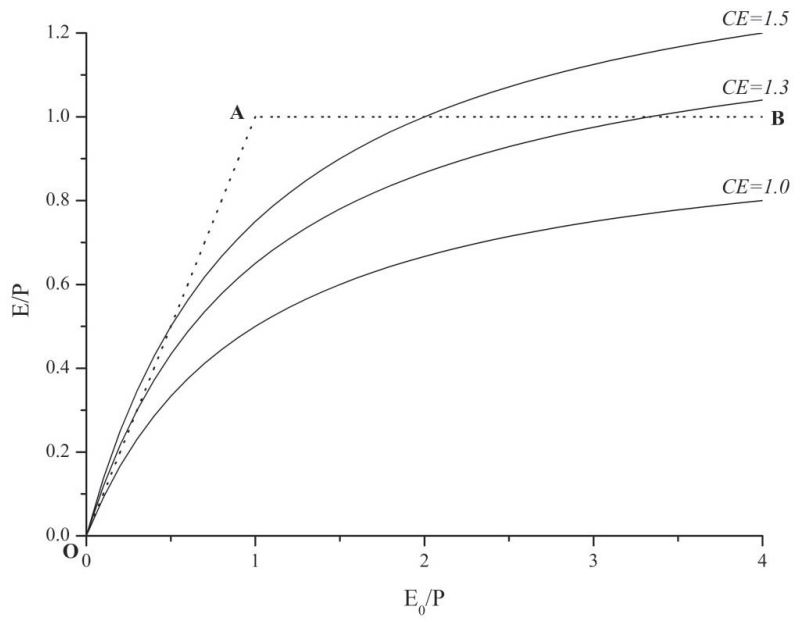

Fig. 4. CCUW hypothesis curves for different $C_{E}$ values. 


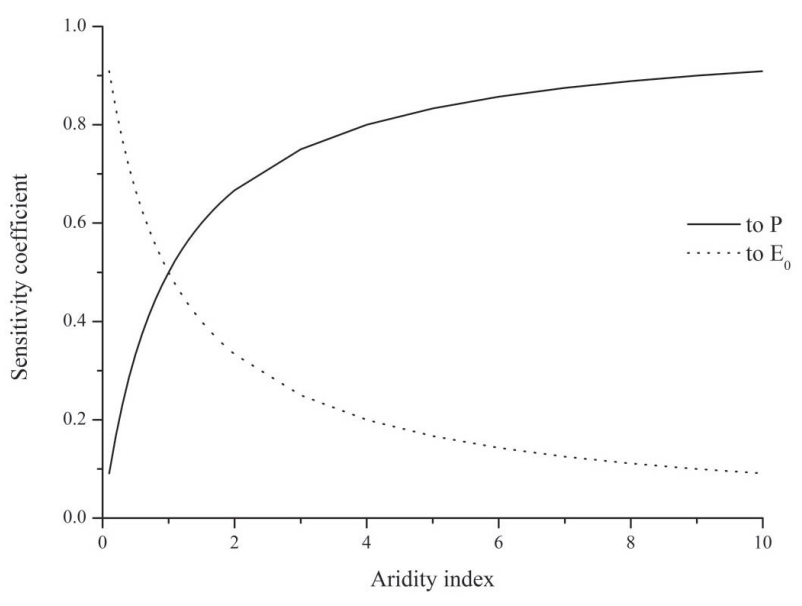

Fig. 5. Sketch of the relationship between sensitivity coefficients of $E$ to climate ( $P$ and $E_{0}$ ) and aridity index $(\phi)$.

while a $10 \%$ increase in $E_{0}$ would result in $3.4 \%$ in actual evapotranspiration.

\section{Regional Differences of the Sensitivities in China}

According to equations (8) and (10), the sensitivity and elasticity coefficients of the 10 regions in China were calculated, and the results are shown in Table 2 . The values of $\partial E / \partial P$ and $\partial E / \partial E_{0}$ in China were $0.16 \sim 0.65$ and $0.02 \sim 0.48$, and the values of $\varepsilon_{P}$ and $\varepsilon_{E_{0}}$ were $0.36 \sim 0.86$ and $0.14 \sim 0.64$.

The northwestern rivers basin is an extremely arid region in China, with an aridity index of 6.39 and much larger than other regions, the results of $\partial E / \partial P$ showed that it is also as large as 0.65 , meaning that if precipitation decreased by $1 \mathrm{~mm}$, actual evapotranspiration would decrease by $0.65 \mathrm{~mm}$. The southeastern rivers basin is the extreme humid region in China, its aridity index is only 0.57 , and the results of $\partial E / \partial P$ showed that it also smallest at 0.19 . For $\partial E / \partial E_{0}$, inversely, the northwestern rivers basin had the smallest value of 0.02 , meaning that if potential evapotranspiration decreased by $1 \mathrm{~mm}$, actual evapotranspiration would decrease by only $0.02 \mathrm{~mm}$. And the southeastern rivers basin had the largest value of 0.48 . Like $\partial E / \partial P$ and $\partial E / \partial E_{0}$, the values of $\varepsilon_{P}$ and $\varepsilon_{E_{0}}$ showed the same trend among these 10 regions.

\section{The Sensitivity of $P$ and $E_{0}$ on $E$ with Aridity Index}

As seen in Table 2, the values of $\partial E / \partial P$ and $\varepsilon_{P}$ in arid regions $(\phi>1)$ were larger than in humid regions $(\phi<1)$. This means that precipitation changes would lead to more changes in evapotranspiration in arid regions. While the values of $\partial E / \partial E_{0}$ and $\varepsilon_{E_{0}}$ in humid regions $(\phi<1)$ were larger than in arid regions $(\phi>1)$. This means that potential evapotranspiration changes would lead to more changes in evapotranspiration in humid regions.

Table 3 and Fig. 3 show the correlation analysis and relationships between the coefficients $\left(\partial E / \partial P, \partial E / \partial E_{0}, \varepsilon_{E}\right.$, and $\left.\varepsilon_{E_{0}}\right)$ and aridity index $(\phi)$, respectively. The results suggest that the coefficients have significant correlations with $\phi$ at the 0.01 level, implying that the sensitivity of climate on $E$ was significantly influenced by aridity. The relationships between the coefficients of $\mathrm{P}(\partial E / \partial P$ and $\varepsilon_{E}$ ) and $\phi$ are significantly nonlinear and positive $(y=a \ln (x+b)+c)$, and the relationships between the coefficients of $E_{0}\left(\partial E / \partial E_{0}\right.$ and $\left.\varepsilon_{E}\right)$ and $\phi$ are significantly nonlinear and negative $(y=-\operatorname{aln}(x+b)+c)$. This means that actual evapotranspiration is more sensitive to precipitation in a drier region and more sensitive to potential evapotranspiration in a wetter region.

\section{Effects of Climate on Evapotranspiration with Aridity Index}

Fig. 5 shows a sketch of the relationship between the sensitivity coefficients of $E$ to climate $\left(P\right.$ and $\left.E_{0}\right)$ and aridity index $(\phi)$. As seen in this sketch, the sensitivity of $E$ to $P$ is increased with the increase of aridity index, and the sensitivity of $E$ to $E_{0}$ is decreased with the increase of aridity index. Before and after the point of $\phi=1$, the comparisons between the sensitivity to $P$ and to $E_{0}$ have opposite results.

According to equation (8), we compared $\partial E / \partial P$ with $\partial E / \partial E_{0}$ and got $(\partial E / \partial P) /\left(\partial E / \partial E_{0}\right)=\left(E_{0} / P\right)^{2}=\phi^{2}$. In accordance with this equation, $\left[(\partial E / \partial P) /\left(\partial E / \partial E_{0}\right)\right]$ can be in direct proportion to the square of an aridity index $\left(\phi^{2}\right)$, which means that in a humid region (i.e., $\phi<1)$, the $\partial E / \partial P$ is smaller than that of $\partial E / \partial E_{0}$. Therefore, evapotranspiration is more sensitive to potential evapotranspiration; in an arid region (i.e., $\phi>1$ ), $\partial E / \partial P$ is larger than $\partial E / \partial E_{0}$, meaning that evapotranspiration is more sensitive to precipitation.

Equation (10) shows that $\varepsilon_{E}$ and $\varepsilon_{E_{0}}$ had a significant correlation with the aridity index $(\phi)$. So $\varepsilon_{E}$ is increased with the increase of aridity index and $\varepsilon_{E}$ is decreased with the increase of an aridity index. Compared with $\varepsilon_{E}$ and $\varepsilon_{E_{0}}$, we could get $\varepsilon_{E} / \varepsilon_{E_{0}}=\phi$. The $\varepsilon_{E}$ and $\varepsilon_{E_{0}}$ had the same value of 0.5 when $\phi \stackrel{\varepsilon_{0}}{=} 1$; whereas $\varepsilon_{E}$ is smaller than that of $\varepsilon_{E_{0}}$ in a humid region $(\phi<1)$. This also means that evapotranspiration is much more sensitive to potential evapotranspiration; and the $\varepsilon_{E}$ is larger than that of $\varepsilon_{E_{0}}$ in an arid region (i.e. $\phi>1$ ), which means evapotranspiration is much more sensitive to precipitation.

\section{Conclusions}

For this study we used a more simple water and energy balance equation to compare the effects of precipitation and potential evapotranspiration on actual evapotranspiration, mathematically and theoretically. And the conclusions can be summarized as follows:

1. In Baiyangdian catchment, a $1 \mathrm{~mm}$ or $10 \%$ increase in precipitation would lead to $0.51 \mathrm{~mm}$ or $6.6 \%$ in actual evapotranspiration, and a $1 \mathrm{~mm}$ or $10 \%$ increase in potential evapotranspiration would lead to $0.14 \mathrm{~mm}$ or $3.4 \%$ in actual evapotranspiration. 
2. The regional differences in the 10 regions of China showed that the effects of climate on actual evapotranspiration had significant spatial heterogeneity and were significantly influenced by the aridity index $(\phi)$.

3. In humid regions $(\phi<1)$, evapotranspiration is more sensitive to potential evapotranspiration, and in arid regions $(\phi>1)$ evapotranspiration is more sensitive to precipitation.

\section{Acknowledgements}

This research was financially supported by the Central Nonprofit Research Institutions Basic Scientific Research Special Fund (CAFYBB2016SY032).

\section{References}

1. MARTINEZ G.F., GUPTA H.V. Toward improved identification of hydrological models: A diagnostic evaluation of the "abcd" monthly water balance model for the conterminous United States. Water Resources Research 46, W08507, 2010.

2. XIONG L., GUO S. Appraisal of Budyko formula in calculating long-term water balance in humid watersheds of southern China. Hydrological processes, 26, 1370, 2012.

3. ZIERNICKA-WOJTASZEK A., ZAWORA T. Thermal Regions in Light of Contemporary Climate Change in Poland. Polish Journal of Environmental Studies, 20 (6), 1627, 2011.

4. WILLIAMSON T.N., NYSTROM E.A., MILLY P.C.D. Sensitivity of the projected hydroclimatic environment of the Delaware River basin to formulation of potential evapotranspiration. Climatic Change, 139 (2), 1, 2016.

5. MISHRA V., LILHARE R. Hydrologic sensitivity of Indian sub-continental river basins to climate change. Global \& Planetary Change, 139, 78, 2016.

6. KOSTER R.D., OKI T., SUAREZ M.J. The Offline Validation of Land Surface Models: Assessing Success at the Annual Timescale. Journal of the Meteorological Society of Japan, 77 (1B), 257, 1999.

7. MILLY P.C.D., BETANCOURT J., FALKENMARK M., HIRSHCH R.M., KUDZEWICZ Z.W., LETTENMAIER D.P., STOUFFER R.J. Climate change: Stationarity is dead: whither water management? Science, 319, 573, 2008.

8. JIANG C., XIONG L., WANG D., LIU P., GUO S., XU C. Separating the impacts of climate change and human activities on runoff using the Budyko-type equations with time-varying parameters. Journal of Hydrology, 522, 326, 2015.

9. XU K., MILLIMAN J.D., XU H. Temporal trend of precipitation and runoff in major Chinese Rivers since 1951. Global Planet Change, 73 (3-4), 219, 2010.

10. IMMERZEEL W.W., VAN BEEK L.P.H., BIERKENS M.F.P. Climate change will affect the Asian water towers. Science, 328 (5984), 1382, 2010.

11. O'GORMAN P.A., SCHNEIDER T. The physical basis for increases in precipitation extremes in simulations of

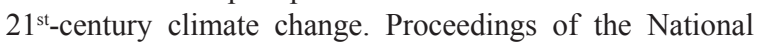
Academy of Sciences of the United States of America, 106 (35), 14773, 2009.
12. RANDAL D., KOSTER MAX J., SUAREZ. A Simple Framework for Examining the Interannual Variability of Land Surface Moisture Fluxes. Journal of Climate, 12 (7), 1911, 1999.

13. TAGUE C., DUGGER A.L. Ecohydrology and Climate Change in the Mountains of the Western USA - A Review of Research and Opportunities. Geography Compass, 4 (11), 1648, 2010.

14. RENNER BERNHOFER Applying simple water-energy balance frameworks to predict the climate sensitivity of streamflow over the continental United States. Hydrology and Earth System Sciences, 16, 2531, 2012.

15. BUDYKO M. Climate and life, Academic press, New York, USA, 1974.

16. ZHANG L., HICKEL K., DAWES W.R. A rational function approach for estimating mean annual evapotranspiration. Water Resources Research, 40, 1, 2004.

17. OUDIN L., ANDREASSIAN V., LERAT J., MICHEL C. Has land cover a significant impact on mean annual streamflow? An international assessment using 1508 catchments. Journal of Hydrology, 357, 303, 2008.

18. ANDREASSIAN V., PERRIN C. On the ambiguous interpretation of the Turc-Budyko non-dimensional graph. Water Resources Research, 48, W10601, 2012.

19. FU B.P. On the calculation of the evaporation from land surface. Sci. Atmos. Sin. 5, 23, 1981 [In Chinese].

20. TOMER M., SCHILLING K. A simple approach to distinguish land use and climate-change effects on watershed hydrology. Journal of Hydrology, 376, 24, 2009.

21. YANG H.B., YANG D.W., LEI Z.D., SUN F.B. New analytical derivation of the mean annual water-energy balance equation. Water resources research, 44, W03410, 2008.

22. SCHAAKE J., LIU C. Development and application of simple water balance models to understand the relationship between climate and water resources, in: New Directions for Surface Water Modeling Proceedings of the Baltimore Symposium, 1989.

23. HU S., LIU C., ZHENG H., WANG Z., YU J. Assessing the impacts of climate variability and human activities on streamflow in the water source area of Baiyangdian Lake. J Geogr Sci 22 (5), 895, 2012.

24. GAO G., FU B., WANG S., LIANG W., JIANG X. Determining the hydrological responses to climate variability and land use/cover change in the Loess Plateau with the Budyko framework. Science of the Total Environment, 557558, 331, 2016.

25. ANDRÉASSIAN V., CORON L., LERAT J., MONINE N.L. Climate elasticity of streamflow revisited - an elasticity index based on long-term hydrometeorological records. Hydrology \& Earth System Sciences Discussions, 12 (4), 3645, 2015.

26. CHEN X., ALIMOHA MMADI N., WANG D. Modeling interannual variability of seasonal evaporation and storage change based on the extended Budyko framework. Water Resources Research, 49 (9), 6067, 2013.

27. DAN L., JI J., XIE Z., CHEN F., WEN G., RICHIEY J.E. Hydrological projections of climate change scenarios over the $3 \mathrm{H}$ region of China: A VIC model assessment. Journal of Geophysical Research Atmospheres, 117 (D11), 11102, 2012.

28. KONAPALA G., MISHRA A.K. Three-parameter-based streamflow elasticity model: application to MOPEX basins in the USA at annual and seasonal scales. Hydrology \& Earth System Sciences Discussions, 20 (6), 1, 2016. 